\title{
Larval ecomorphology of 13 Libellulidae (Anisoptera, Odonata) of the Middle Rio Doce Valley, Minas Gerais, Brazil
}

\author{
Giacomini, HC. ${ }^{\text {a* }}$ and De Marco Jr., $P .{ }^{\mathrm{b}}$ \\ aDepartamento de Ecologia, Campus de Rio Claro, Universidade Estadual Paulista “Júlio de Mesquita Filho”, \\ Av. 24-A, 1515, CEP 13506-900, Rio Claro, SP, Brazil \\ bLaboratório de Ecologia Teórica e Síntese, Departamento de Biologia Geral, Campus II, Universidade Federal de Goiás, \\ Rod. Goiânia-Nerópolis Km 5, Setor Itatiaia, CP 131, CEP 74001-970, Goiânia, GO, Brazil \\ *e-mail: hgiacomini@gmail.com \\ Received June 22, 2006 - Accepted July 17, 2006 - Distributed February 29, 2008
}

(With 3 figures)

\begin{abstract}
In the lakes of the Middle Rio Doce, Minas Gerais (MG), two groups of larval Libellulidae are distinguished by preferences of habitat use: one uses mainly aquatic macrophytes and the other uses the bottom substrate. The goal of this work was to verify if there is a morphological distinction between the two groups of species. Thirteen body measures were taken from the larvae and analyzed. No difference was found between the two groups of species regarding the body size, but shape differences were observed for two morphological variables. The species that use mainly macrophytes tend to have larger relative measures of the labium and smaller measures of the abdomen width. Advantages in resource obtainment and in vulnerability to predation are probably the explanations for the morphological divergence among these larval groups.
\end{abstract}

Keywords: Ecomorphology, Libellulidae, macrophyte, Rio Doce.

\section{Ecomorfologia larval de 13 Libellulidae (Anisoptera, Odonata) do Vale do Médio Rio Doce, MG, Brasil}

\begin{abstract}
Resumo
Nos lagos do Médio Rio Doce (MG), dois grupos de larvas de Libellulidae apresentam diferenças no uso do habitat: um utiliza preferencialmente macrófitas aquáticas e o outro utiliza a superfície do fundo. O objetivo deste trabalho foi verificar se existe uma distinção morfológica entre estes dois grupos. Treze medidas morfológicas foram tiradas das larvas e analisadas. Nenhuma diferença, com relação ao tamanho corporal, foi encontrada entre os dois grupos, embora diferenças de forma tenham sido observadas com relação a duas variáveis morfológicas. As espécies que usam principalmente macrófitas tendem a possuir maiores medidas relativas do lábio e menores medidas da largura do abdome, o oposto ocorrendo com as larvas habitantes do fundo. Vantagens na captura de presas e na vulnerabilidade à predação são provavelmente as explicações para a divergência morfológica observada entre os dois grupos de larvas.
\end{abstract}

Palavras-chave: Ecomorfologia, Libellulidae, macrófitas, Rio Doce.

\section{Introduction}

For an organism to persist and to reproduce in an environment, it should have at least a compatible morphology with the manner in which it obtains the resources and uses the habitat. If the communities are structured by natural selection pressures, then it is expected that the species that use similar resources, in similar habitats, should have convergent morphologies, as a way to achieve maximum efficiency in the conversion of resources into descendents, but with a limit to the similarity imposed mainly by competition pressure (Hutchinson and Macarthur, 1959; Karr and James, 1975; Ricklefs and Miles, 1994). This means that the morphology of the species that co-occur in a community should be strongly determined by biological interactions inside this sys-

tem (Abrams, 1986; Strong et al., 1979; McPeek, 1995; Douglas and Matthews, 1992).

Larval odonates present a great morphological diversity due to both phylogenetic and ecological differences. In the region of the Middle Rio Doce, De Marco and Latini (1998) identified two groups of Anisoptera according to habitat type: i) species characteristics of areas with aquatic macrophytes and ii) species characteristics of the bottom substrate, found as much in areas with macrophytes as in areas without them. The presence of macrophytes provides conditions that affect the availability of prey and susceptibility to predation (Wellborn and Robinson, 1987; Dionne et al., 1990; Henrikson, 1988; Gilinsky, 1984). The architecture of this substrate 
allows the larva to explore a large extension of the water column, and therefore a larger habitat volume, offering countless possibilities of corporal orientation in the three dimensions. The structural complexity generated by macrophytes reduces predation risk (Gilinsky, 1984), mainly by fishes, the principal predators of Odonata larvae (Morin, 1984; McPeek, 1990b).

The Odonata larvae that live on the bottom are more restricted to the surface of the sediment due to the absence of a developed vertical substrate. Some species (sprawlers) lean upon detritus and sediments while others (burrowers) bury themselves. Because fish can see well in this environment, the morphology of larval odonates adapted to the depth must offer an efficient camouflage and their behavior must be less active.

In the Libellulidae, the great majority of species belong to the sprawler type, resting upon the bottom substrate with their legs laterally extended (Cummins and Merritt, 1984; Carvalho and Nessimian, 1998). They are capable of utilizing both the bottom substrate and the aquatic vegetation, but each species or genus presents a different degree of preference for one or another substrate (De Marco and Latini, 1998). The classification based on this preference, discrete and not reflecting its degree of continuity, is pertinent in view of the essential morphological adaptations to usage of a substrate type. The use in a higher frequency of a type of substrate must reflect a selection of morphological and behavioral types at appropriate environments by competition pressures and mainly by predation.

Morphology can be analyzed through two factors: the body size and the corporal shape. The morphological characteristics of a species can be described by a set of morphological variables that represent the linear measures of several individualized corporal parts. Size is a factor that produces positive correlations among the variables, while shape is a factor related to the proportions among these variables (Jolicoeur, 1963).

Individuals of smaller body size are more vulnerable to predation by larger larval Odonata (Morin, 1984; Benke et al., 1982). The latter, in turn, are more vulnerable to fish predation, because they are preferred in relation to smaller ones (Morin, 1984). On this basis, it is expected that the species that use macrophytes must have a larger corporal size than those associated to the bottom substrate, because of major risk by odonate predation in the first case and by fish predation in the second. However, it might happen that a small body size could be a benefit in the middle of a tangle of vegetation, conferring better ability and mobility to the larva that lives in macrophytes. The efficiency in the use of the substrate and in foraging, just like the camouflage capacity, also depends on the corporal shape, which can therefore translate into differences between the environment types utilized.

The main goal of this work is to verify if, for thirteen species of Libellulidae in the Middle Rio Doce, there is a morphological distinction, in size and in shape, that separates the species that live preferably in macrophytes from those that live on the bottom substrate. We hope to settle which morphological variables might be better related with the habitat distinctions, and how these variables are related to each other to produce differences of shape among the species groups. It is likely that the morphological identity of the groups is limited to a restricted number of variables, because factors like phylogenetic constraints and limits to similarity are important in determining general morphology and the co-occurrence success of species in a community.

\section{Material and Methods}

The larvae utilized in this study were collected in lakes of the lacustrine system of the Middle Rio Doce, Minas Gerais, Brazil, composed of around 130 lakes. Of all the lakes utilized, one (Carioca lake) is located inside a remnant of humid tropical forest, the Parque Estadual do Rio Doce (PERD), which has an area of 35,000 ha. The others (the lakes Águas Claras, Capim, Crentes and Nova) are located south of the park, in a eucalyptus plantation area belonging to the Companhia Agrícola Florestal de Santa Bárbara (CAF).

In the marginal regions of these lakes, two types of environment were identified: i) areas covered by macrophyte beds and ii) areas without macrophyte cover, with higher influence of the marginal forest cover. The areas with macrophytes are characterized by having low depth and declivity, with little projection of the marginal trees upon the water surface, so they receive a higher solar irradiation. These factors allow the fixation of a dense tangle of macrophytes, mainly Eleocharis R. Br. 1810, besides a high autochthonous productivity. The bottom substrate material in this environment is mainly composed of Eleocharis in decomposition. The areas without macrophytes have a more inclined floor and an effective forest projection upon the water surface, which stays shady most of the day. The bottom material in this environment is mainly composed of leaves and branches of the marginal trees and sediments (sand or clay).

The larvae were collected in June and September of 1994, from August through November of 1995 and from February through June of 1996, in the Carioca lakes (PERD). In the CAF area, the samples were taken in September and October of 2000 from the Águas Claras, Crentes, Capim and Nova lakes. The identification of genera and species was made with the assistance of keys for North American species (Needham et al., 2000; Westfall, 1984) and for Brazilian species (Carvalho and Calil, 2000), and also through the reference collection of the laboratory. Nevertheless, the final identification of some species was made based on adults obtained from larvae that were raised in the laboratory.

Only larvae in the last instar were used for the morphometry. This standardization measure avoids the appearance of spurious relations among the morphological variables, by allometric effects linked to drastic size differences. The last instar was chosen because it is easier to 
determine this stage and to take its morphological measures. The morphometric measures used are illustrated in Figure 1 and were taken using a stereoscopic microscope, with the precision of $0.1 \mathrm{~mm}$. They were chosen based on De Marco (1992), because the general construction of the body and the labium are well characterized, with these measures of the straight distances among dots of recognizable homology, or landmarks, as proposed by Strauss (1982). The total length and width of the head (1 and 2, in Figure 1) are measures that represent the general shape of the head, which jointly with the longitudinal length of the eye (3), indicate the relative size of the eyes and its position (more lateral or more frontal). The size and the position of the eyes are traditionally related to the foraging mode, to the manner in which prey is caught and to habitat type (Pritchard, 1966; De Marco, 1992). The length of the femur $(4,5,6)$, the width and the length of the largest abdominal segment $(7,8)$ are measures of the size of the legs and the abdomen, which are related to the manner in which the substrate is used (Corbet, 1999). The labium measures $(11,12,13)$ are related to the maximum size of the prey (Blois, 1985; Pritchard, 1965) and to the maximum reactive volume within which the larva is able to strike the attack upon the prey. The length of the lateral spines (9 and 10) is mainly related to reduced susceptibility to predation (Johansson, 2002). The presence of the
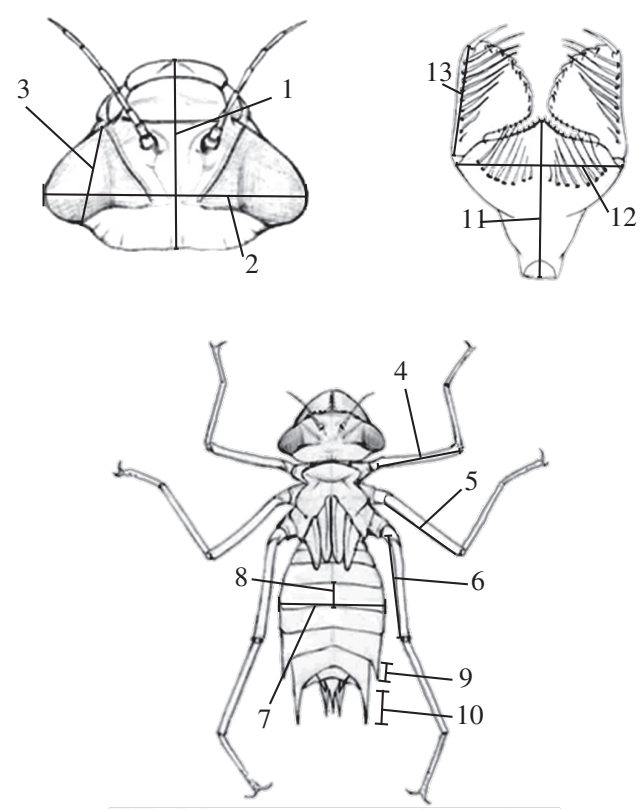

Figure 1. Representation of the morphological characters used for the morphometry. 1) Total length of head; 2) Head width; 3) Longitudinal length of eye; 4) Length of anterior femur; 5) Length of medium femur; 6) Length of posterior femur; 7) Width of the largest abdominal segment; 8) Length of the largest abdominal segment; 9) Length of lateral spine of the eighth abdominal segment; 10) Length of lateral spine of the ninth abdominal segment; 11) Total length of the pre-mentum; 12) Distal width of the prementum; and 13) Length of the lateral lobe. spines has also been related to the hydrodynamic process of swimming, while the larva feeds near water surface through a coordinated jet propulsion (Corbet, 1999). The developed lateral spines can avoid a reverse in direction of the body in the water when the labium is protracted. It is possible that the abdomen shape also has a decisive influence in this process.

The ecological classification of species was made based on De Marco and Latini (1998), Carvalho and Nessimian (1998), De Marco (1992) and personal observations. Our sample unit for all analyses is the species. The use of any sample set that represented an intraspecific variation would constitute a serious problem of pseudo-replication (Hurlbert, 1984) for the purposes of this work. The morphologic measures considered for analysis should be, therefore, the averages among the individuals of each species. Even species could not be considered independent samples because they share different degrees of phylogenetic kinship (Harvey and Pagel, 1991). However, in the absence of a phylogeny for the genera studied here, this could be considered appropriate.

Table 1 shows the species considered in this work, as well as the ecological category, the sources by which this classification was made and the number of individuals used for morphometry.

For the determination of the species body size, we used a Principal Components Analysis (PCA) with the natural logarithms of the morphological variables. In morphological data, the variables normally present positive correlations, which results from the effect of body size. A large part of the variation in these data is basically due to size differences, mainly when species are phylogenetically close. The first axis generated in a PCA of morphological data can be, then, interpreted as a factor of body size (Jolicoeur, 1963). The application of this technique for size determination has been corroborated by other authors of works in multivariate morphometry (Diniz-Filho et al., 1994; Atchley et al., 1981).

The comparisons of shape among the species were made controlling for the effect of body size. For this, we made linear regressions among the natural logarithms of the original variables and the factor of size generated in the PCA. Variation in shape was determined based on the residuals of the regressions. For the comparison of body size among the groups, we used a t-test with the scores of the axis of size in PCA. The comparison of shape was made through a t-test with the residuals of regressions. The result of the tests can indicate what variables are more associated with the separation of the ecological groups.

Usually, the method employed to analyze the significance of differences in shape, with multivariate data, is a discriminant analysis, or a canonical variate analysis (Albrecht, 1980; Manly, 1994). Unfortunately, this could not be performed, as the sample size is insufficient when compared to the number of variables, which are highly correlated among each other, leading to a redundancy 
constraint. As we are interested in including all the thirteen morphological variables here described, we did not have any other choice than to apply univariate tests, which are still capable of showing shape differences, but without the advantage of fully exploiting the data correlation structure.

\section{Results}

The PCA analysis showed that the proportion of the variance explained by the first morphometric axis is $83 \%$, which means that the morphological variables are all strongly correlated. The correlations of these variables with the generated axis are all high and have the same signal (positive, Table 2, Figure 2) reinforcing the interpretation of this axis in PCA as a factor of body size.
Correlation values smaller than 0.8 were found only for the length of spines of the eighth and ninth abdominal segments, suggesting that differences in these variables are important in the variation of shape among the species studied. In general, corporal size is responsible for almost all the morphological variation existing in data.

Using the first axis of PCA as a measure of corporal size, we did not observe any difference among the species that could distinguish the ecological groups of this study ( $t$-test, Table 3 ). Nevertheless, among the residuals of the variables there are some differences. The width of the largest abdominal segment and the total length of the prementum are the principal variables for the morphological separation of the two groups. They showed a significant effect, even considering a Bonfferoni's correction for this multiple testing situa-

Table 1. Species collected in the lakes of Middle Rio Doce and the classification related to the habitat use. *References: literature source from where the classification was taken - 1, Carvalho and Nessimian (1998); 2, De Marco and Latini (1998); 3, personal observations 4, De Marco (1992). 'n' - number of individuals used for the morphometry.

\begin{tabular}{|c|c|c|c|}
\hline Species & Habitat & References* & $\mathbf{n}$ \\
\hline Erythrodiplax sp. & Macrophyte & 1 & 2 \\
\hline Idiataphe amazonica & Macrophyte & 2 & 4 \\
\hline Miathyria simplex & Macrophyte & 1,4 & 4 \\
\hline Micrathyria sp. 1 & Macrophyte & 1,4 & 4 \\
\hline Micrathyria sp. 2 & Macrophyte & 1,4 & 1 \\
\hline Tauriphila australis & Macrophyte & 3 & 1 \\
\hline Tramea binotata & Macrophyte & 2,3 & 4 \\
\hline Erythemis peruviana & Macrophyte & 1 & 1 \\
\hline Brachymesia furcata & Bottom & 2,3 & 4 \\
\hline Diastatops obscura & Bottom & 1,2 & 4 \\
\hline Orthemis discolor & Bottom & 1,3 & 1 \\
\hline Perithemis mooma & Bottom & 1,3 & 4 \\
\hline Dythemis multipunctata & Bottom & 1 & 4 \\
\hline
\end{tabular}

Table 2. Values of the variables loads in the axis generated by the Principal Components Analysis, the proportion of the variance explained by the axis and the values of $\mathrm{R}^{2}$ of regression between the scores of PCA and the variables logarithms.

\begin{tabular}{lcc}
\multicolumn{1}{c}{ Variables } & Load & $\mathbf{R}^{\mathbf{2}}$ \\
\hline Total length of head & 0.941 & 0.885 \\
Head width & 0.955 & 0.912 \\
Longitudinal length of eye & 0.861 & 0.741 \\
Length of anterior femur & 0.931 & 0.866 \\
Length of medium femur & 0.972 & 0.946 \\
Length of posterior femur & 0.929 & 0.863 \\
Width of the largest abdominal segment & 0.920 & 0.846 \\
Length of the largest abdominal segment & 0.903 & 0.816 \\
Length of lateral spine of the eighth abdominal segment & 0.789 & 0.623 \\
Length of lateral spine of the ninth abdominal segment & 0.683 & 0.467 \\
Prementum total length & 0.967 & 0.935 \\
Distal width of prementum & 0.967 & 0.936 \\
Length of the lateral lobe & 0.985 & 0.970 \\
Explained variance & 0.831 & - \\
\hline
\end{tabular}


tion. Dividing the overall test's alpha $(0.05)$ by $13-$ the number of morphological variables - gives a critical level of 0.0038 for each variable. As the variables are not independent (they are really correlated), the correct critical level should be somehow higher than that presented above, and because of this, we consider the effect of the total length of prementum as significant $(\mathrm{p}=0.005$, Table 3$)$.
In our case, the result of the $t$-test goes beyond indicating the statistical significance of the differences. As the number of samples is the same for all the variables, the absolute values of " $t$ " can be used like determinants of an importance scale in the morphological separation of the groups. Thus, beyond the two variables already cited, two other variables, the longitudinal length of the eye and the length of the anterior femur, can be distin-

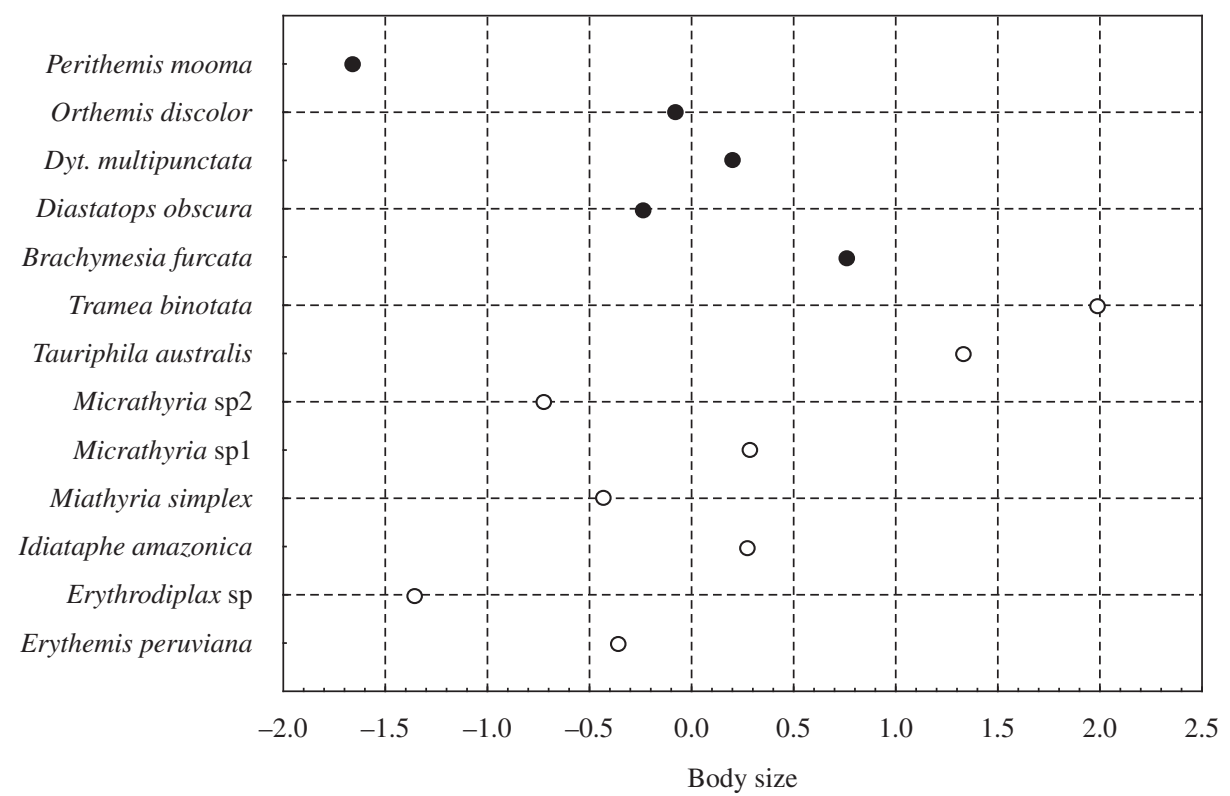

Figure 2. Axis scores generated in PCA made with the logarithms of the morphological variables. In this work this axis can be considered as a factor of body size. Open circles are the species that use preferentially macrophytes and black circles are species that use preferentially the bottom substrate.

Table 3. Results of $t$-tests with the body size and with the residuals of morphological variables. Within the second and third columns are presented the averages for each species group. The marked values indicate a significant difference.

\begin{tabular}{lcccc}
\hline \multicolumn{1}{c}{ Variables } & Macrophyte & Bottom & $\mathbf{t}$ & $\mathbf{p}$ \\
\hline Body size & 0.129 & -0.206 & 0.570 & 0.580 \\
Total length of head & 0.008 & -0.013 & 0.504 & 0.624 \\
Head width & 0.016 & -0.025 & 1.450 & 0.175 \\
Longitudinal length of eye & 0.041 & -0.066 & 2.113 & 0.058 \\
Length of anterior femur & -0.029 & 0.047 & 1.988 & 0.072 \\
Length of medium femur & -0.004 & 0.007 & 0.382 & 0.710 \\
Length of posterior femur & -0.007 & 0.012 & 0.382 & 0.710 \\
Width of the largest & -0.046 & 0.074 & 4.074 & $0.002^{*}$ \\
abdominal segment & & & & \\
Length of the largest & -0.022 & 0.035 & 1.520 & 0.157 \\
abdominal segment & & & & \\
Length of lateral spine of the & 0.007 & -0.010 & 0.165 & 0.872 \\
eighth abdominal segment & & & & \\
Length of lateral spine of the & -0.001 & 0.001 & 0.012 & 0.991 \\
ninth abdominal segment & & & & \\
Prementum total length & 0.035 & -0.056 & 3.553 & $0.005^{*}$ \\
Distal width of prementum & 0.008 & -0.012 & 0.528 & 0.608 \\
Length of the lateral lobe & 0.007 & -0.012 & 0.871 & 0.402 \\
\hline
\end{tabular}


guished from the rest, although they do not present significant differences between the larval groups.

The residuals of the most important variables for the separation of groups present significant correlations among each other (Table 4). The width of the largest abdominal segment and the length of the anterior femur have negative correlations with the longitudinal length of the eye and total length of prementum. Discounting the effect of body size, bottom substrate species tend to have larger values of the first two variables and smaller values of the last two, as noticed in Figure 3 and in the averages showed in Table 3.

\section{Discussion}

The results show a distinction of shape among species that prefer macrophytes from those that prefer the bottom substrate, but this distinction is restricted to only two morphological variables. The most intriguing question, however, is related to the correlations among the re-

Table 4. Correlations between the residuals of the morphological variables. TLH - Total length of head; HW - Head width; LLE - Longitudinal length of eyes; LAF - Length of anterior femur; LMF - Length of medium femur; LPF - Length of posterior femur; WLAS - Width of the largest abominal segment; LLAS - Length of the largest abdominal segment; LLS8 - Length of lateral spine of the eighth abdominal segment; LLS9 - Length of lateral spine of the ninth abdominal segment; TLP - Total length of the prementum; DWP - Distal width of prementum; LLL - Length of lateral lobe. The residuals come from linear regressions between the body size factor and the logarithms of the original variables. The marked correlations are significant at $5 \%$ significance level. The number of significant correlations (15) is much greater than that expected purely by chance (less than four).

\begin{tabular}{lccccccccccccc}
\hline \multicolumn{1}{c}{ - } & TLH & - & - & - & - & - & - & - & - & - & - & - & - \\
TLH & 1 & HW & - & - & - & - & - & - & - & - & - & - & - \\
HW & -0.1 & 1 & LLE & - & - & - & - & - & - & - & - & - & - \\
LLE & 0.26 & 0.3 & 1 & LAF & - & - & - & - & - & - & - & - & - \\
LAF & -0.4 & -0.3 & $\mathbf{- 0 . 8 8}$ & 1 & $\mathbf{L M F}$ & - & - & - & - & - & - & - & - \\
LMF & $\mathbf{- 0 . 5 9}$ & -0.18 & -0.28 & 0.45 & 1 & $\mathbf{L P F}$ & - & - & - & - & - & - & - \\
LPF & -0.42 & 0.08 & -0.08 & 0.25 & $\mathbf{0 . 5 8}$ & 1 & $\mathbf{W L A S}$ & - & - & - & - & - & - \\
WLAS & 0.1 & -0.33 & $\mathbf{- 0 . 7 7}$ & $\mathbf{0 . 7}$ & -0.01 & 0.11 & 1 & $\mathbf{L L A S}$ & - & - & - & - & - \\
LLAS & 0.44 & -0.3 & -0.4 & 0.38 & -0.19 & 0.2 & $\mathbf{0 . 6 8}$ & 1 & $\mathbf{L L S 8}$ & - & - & - & - \\
LLS8 & 0.02 & -0.37 & 0.15 & -0.21 & -0.37 & $\mathbf{- 0 . 6 8}$ & -0.15 & -0.39 & 1 & $\mathbf{L L S 9}$ & - & - & - \\
LLS9 & $\mathbf{- 0 . 6 7}$ & -0.31 & -0.05 & 0.11 & 0.49 & -0.07 & -0.3 & $\mathbf{- 0 . 7 2}$ & 0.5 & 1 & TLP & - & - \\
TLP & 0.09 & 0.25 & $\mathbf{0 . 5 8}$ & $\mathbf{- 0 . 6 6}$ & -0.15 & -0.21 & $\mathbf{- 0 . 8 6}$ & -0.46 & 0.11 & 0.07 & 1 & $\mathbf{D W P}$ & - \\
DWP & 0.19 & 0.5 & -0.07 & -0.17 & -0.22 & -0.19 & -0.12 & -0.04 & -0.45 & -0.34 & 0.3 & 1 & LLL \\
LLL & 0.34 & $\mathbf{0 . 6 9}$ & 0.25 & -0.46 & $\mathbf{- 0 . 6 9}$ & -0.37 & -0.2 & -0.02 & -0.14 & -0.55 & 0.37 & $\mathbf{0 . 7 6}$ & 1 \\
\hline
\end{tabular}
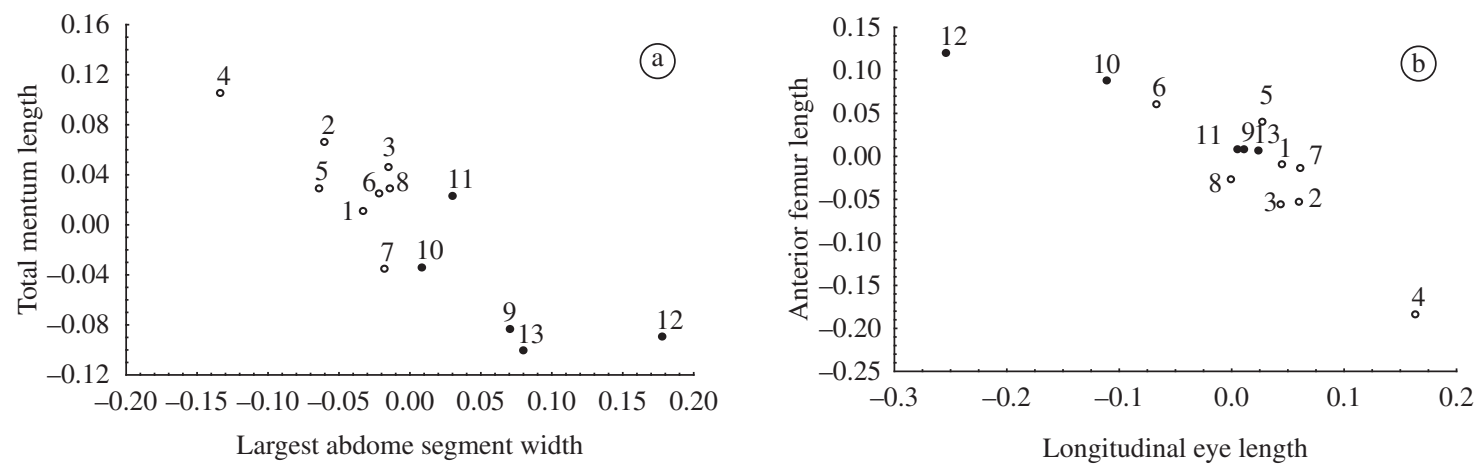

Figure 3. Relations among the residuals of the four principal variables in the separation of the ecological species groups. The dots in the graphics represent the data relative to each species: 1) Erythemis peruviana; 2) Erythrodiplax sp.; 3) Idiataphe amazonica; 4) Miathyria simplex; 5) Micrathyria sp1; 6) Micrathyria sp2; 7) Tauriphila australis; 8) Tramea binotata; 9) Brachymesia furcata; 10) Diastatops obscura; 11) Dythemis multipunctata; 12) Orthemis discolor; and 13) Perithemis mooma. Open circles are the species that use preferentially macrophytes and black circles are species that use preferentially the bottom substrate. 
siduals of the variables. Firstly, it is interesting to exclude the possibility of methodological artifacts in relation to the studied residuals. If, hypothetically, we consider the size of each species as being fixed inside the analysis as it proceeded, an increase in the residual of a given variable should be accompanied with the decrease in the residual of at least another variable, otherwise the species would have its size "increased." The change in the pattern of the residuals among different species could be caused purely at random or as a function of differences in larval development independent of functional questions, respecting the conditions of maintenance in the corporal size. Such changes would produce random variations of corporal shape. However, the morphological shape presented here correlated variations among the species, which are not expected in the hypothesized setting of casual variations. The correlations were significant just among some variables, including those most important to the separation of the functional groups studied. All this makes us believe that the correlations are not mere mathematical artefacts, but a result of biological restrictions to the morphology of these species.

At first sight, the cause of correlations could be attributed to differences in the allometry of the variables. In this case, variables of which residuals are correlated in a negative way should respond in an opposite manner to corporal growth, which means that they present an inverse allometry. However, this does not seem to be a probable cause. Firstly, the residuals were taken from regressions among the logarithms of the variables and the factor of size generated from these logarithms. These residuals are, therefore, free from the effects of allometric nonlinearity. Second, if allometry had effects in the correlations, the groups of species should differ in size, since they are significantly different for the residuals of some variables. Such differentiation of size, however, did not occur.

Given the difference presented between the two groups of species, the most probable explanation for the correlations should be ecological. These correlations probably occur by functional restrictions of corporal shape, being related to selective pressures associated with the type of habitat used by a species. Species that use macrophytes with higher frequency have a larger length of prementum and smaller width of abdomen. A prementum with larger length allows the larva to reach prey at longer distances, with a larger field of attack that is proportional to the extension of the protracted labium (Pritchard, 1964). This, however, does not explain why benthonic larvae do not have a more extensive prementum.

The larvae that live on the bottom substrate are under higher risk of detection by visual predators like fish. They should have more cryptic habits and be less active. These species, mainly those who live buried in the sediment or in detritus, use predominantly tactile mechanisms for prey detection (Bay, 1974; Corbet, 1999). This strategy probably restricts the quantity of perceptible prey, but also reduces the susceptibility to predation. The prey, to be captured, must come close enough to the larva to generate a tactile stimulus. In this situation, having an extensive lip as it occurs in species that live in plants should not be selectively preponderant (Pritchard, 1965).

The opposite occurs in the midst of aquatic vegetation, in which the prey, mainly zooplankton, can be in innumerable positions around a larva. In addition, the risk of being predated, mainly by fish, is reduced by virtue of the structural complexity provided by vegetation (Gilinsky, 1984; Dionne et al., 1990). In this system, the larva can adopt more active foraging, in which the capacity of prey capture is enhanced by a more extended labium associated with a better visual detection. More active species normally have bigger eyes (Corbet, 1999). In this work, species that live in macrophytes have larger average residuals for longitudinal length of eye, this being one of the four principal variables for the separation of ecological groups, as was demonstrated by De Marco (1992). Another variable, the length of the anterior femur, had larger average residuals in the group of species that live on the bottom substrate. This can be related to an improved tactile detection of prey, since the forelegs are related to this function (Pritchard, 1965).

In a general way, the adaptations thus far discussed reinforce the idea that the Libellulidae species that inhabit macrophytes have more active behavior, the opposite occurring with the species with benthonic habits. Such a behavioral pattern was observed in Odonata species that inhabit water bodies without fishes in contraposition to those species that inhabit environments with fishes (McPeek, 1990a; McPeek, 1990b; Pierce, 1988; Pierce et al., 1985; Henrikson, 1988). Since aquatic vegetation represents a refuge against insectivorous fishes (Pierce, 1988; Gilinsky, 1984; Sazima and Zamprogno, 1985), it seems valid that predation upon Odonata is the principal selective pressure responsible for the differences in morphological patterns presented among the groups of species associated with different types of microhabitat.

The bottom substrate species have a greater width of abdomen. This characteristic might be associated with a greater propulsion velocity of larva in the water. The jet propulsion is the fastest locomotion means of Anisoptera larvae, being crucial in eventual escapes. The propelling power that produces the water jet by the larval rectum is generated by the contraction of the abdominal dorsoventral musculature (Mill and Pickard, 1975; Olesen, 1972). A larger abdomen has a wider area of insertion for this musculature, which should raise the power of propulsion. Such a characteristic can be advantageous in an environment where the risk of perception by predator fish is higher. At the moment of attack by the predator, the larva can make use of its powerful propulsion to escape to a closer shelter (branches, detritus or aquatic vegetation).

However, this last hypothesis is in contradiction to behavioral patterns observed in Zygoptera species. McPeek (1990a) showed that some species of Enallagma 
Charpentier, 1840 that usually live in lakes with insectivorous fish species remain immovable at the moment of predator approximation, which lessens the probability of capture from fish. Another group belonging to this genus, adapted to live in lakes without fishes, swims in an attempt to escape when a predator comes closer. This last habit, efficient against anisopteran predators (Aeshnidae), raises the chance of being captured by fishes. The swimming velocity is also higher in species adapted to lakes without fishes (McPeek et al., 1996). Similar studies with Anisoptera larvae are necessary to verify the efficiency of the propulsion jet in the escape from predator fishes. Another necessity is the experimental verification of the functional relations among the abdomen width, other morphometric variables, and the larva's propulsion velocity.

In another work, McPeek (1995) showed that the adaptation to environments without fishes developed independently in different groups of Enallagma. The behavioral and morphological similarities of these species overcame phylogenetic constraints within the genus. This shows that selective pressures similar to those postulated for the system studied here can promote an adaptive convergence evident in behavior and morphology. Contrary to the aforesaid work, however, we don't dispose of a phylogeny for the species here studied. Only in this way would it be possible to infer if the groups discriminated from their habitat use represent two distinct phylogenetic strains. In an affirmative case, the functional relations between morphology and ecology of the groups would become obscure.

\section{References}

ABRAMS, PA., 1986. Character displacement and niche shift analyzed using consumer-resource models of competition. Theoretical Population Biology, vol. 29, no. 1, p. 107-160.

ALBRECHT, GH., 1980. Multivariate analysis and the study of form, with special reference to canonical variate analysis. American Zoologist, no. 20, no. 4, p. 679-693.

ATCHLEY, WR., RUTLEDGE, JJ. and COWLEY, DE., 1981. Genetic components of size and shape. II. Multivariate patterns in the rat and mouse skull. Evolution, vol. 35, no. 6, p. $1035-1055$.

BAY, EC., 1974. Predator-prey relationships among aquatic insects. Annual Review of Entomology, vol. 19, p. 441-453.

BENKE, AC., CROWLEY, PH. and JOHNSON, DM., 1982. Interactions among coexisting larval Odonata: an in situ experiment using small exclosures. Hydrobiologia, vol. 94, no. 2, p. 121-130.

BLOIS, C., 1985. The larval diet of three anisopteran (Odonata) species. Freshwater Biology, vol. 15, no. 4, p. 505-514.

CARVALHO, AL. and CALIL, ER., 2000. Chaves de identificação para as famílias de Odonata (Insecta) ocorrentes no Brasil, Adultos e larvas. Papeis Avulsos de Zoologia, São Paulo, vol. 41, p. 15, p. 223-241.

CARVALHO, AL. and NESSIMIAN, JL., 1998. Odonata do estado do Rio de Janeiro, Brasil: Hábitats e Hábitos das larvas.
In Oecologia Brasiliensis. CARVALHO, AL. and NESSIMIAN, JLCP. (eds), PPGE-UFRJ. Rio de Janeiro, p. 3-28.

CORBET, PS., 1999. Dragonflies: behavior and ecology of Odonata. Comstock Publ. Assoc., Ithaca, NY.

CUMMINS, KW. and MERRITT, RW., 1984. Ecology and distribution of aquatic insects. In An Introduction to the Aquatic Insects of North America. Merrit, RW. and Cummins, KWCP. (eds), p. 59-65. Kendall / Hunt Publishing Company VL Dubuque, Iowa.

DE MARCO, PJR., 1992. Estrutura de Comunidade $e$ Coocorrência de Espécies em Larvas de Odonata: Uma Abordagem Morfológica. 92 p. (Dissertação de mestrado) UNICAMP, Campinas, SP.

DE MARCO, PJR. and LATINI, AO., 1998. Estrutura de Guildas e Riqueza em Espécies em uma Comunidade de Larvas de Anisoptera (Odonata). In Oecologia Brasiliensis. NESSIMIAN, JL. and CARVALHO, ALCP. (eds), PPGEUFRJ. Rio de Janeiro, p. 101-112.

DINIZ-FILHO, JAF., VON ZUBEN, CJ., FOWLER, HG., SCHLINDWEIN, MN. and BUENO, OC., 1994. Multivariate morphometrics and allometry in a polymorphic ant. Insectes Sociaux, vol. 41, no. 2, p. 153-163.

DIONNE, M., BUTLER, M. and FOLT, C., 1990. Plant-specific expression of antipredator behaviour by larval damselflies. Oecologia (Berlin), vol. 3, no. 3, p. 371-377.

DOUGLAS, ME. and MATTHEWS, WJ., 1992. Does morphology predict ecology? Hypothesis testing within a freshwater stream fish assemblage. Oikos, vol. 65, no. 2, p. 213-224.

GILINSKY, E., 1984. The role of fish predation and spatial heterogeneity in determining benthic community structure. Ecology, vol. 65, no. 2, p. 455-468.

HARVEY, PH. and PAGEL, MD., 1991. The comparative method in evolutionary biology. Oxford Univ. Press, Oxford, UK.

HENRIKSON, BI., 1988. The absence of antipredator behaviour in the larvae of Leucorrhinia dubia (Odonata) and the consequences for their distribution. Oikos, vol. 51, no. 2, p. $179-183$.

HURLBERT, SH., 1984. Pseudoreplication and the design of ecological field experiments. Ecological Monographs, vol. 54, no. 2 , p. $187-211$.

HUTCHINSON, GE. and MACARTHUR, RH., 1959. A theoretical ecological model of size distributions among species of animals. The American Naturalist, vol. 93, no. 869, p. $117-125$.

JOHANSSON, F., 2002. Reaction norms and production costs of predator-induced morphological defences in a larval dragonfly (Leucorrhinia dubia: Odonata). Canadian Journal of ZoologyRevue Canadienne de Zoologie, vol. 80, no. 5, p. 944-950.

JOLICOEUR, P., 1963. The multivariate generalization of the allometry equation. Biometrics, vol. 19, no. 1-4, p. 497-499.

KARR, JR. and JAMES, FC., 1975. Eco-morphological configurations and convergent evolution in species and communities. In Ecology and Evolution of Communities. DIAMOND, JM. and CODY, MLCP. (eds), Harvard University Press VL -, p. 258-291. 
MANLY, BJF., 1994. Multivariate Statistical Methods: A Primer. Chapman and Hall, London.

McPEEK, MA., 1990a. Behavioral differences between Enallagma species (Odonata) influencing differential vulnerability to predators. Ecology, vol. 71, no. 5, p. $1714-1726$

-, 1990b. Determination of species composition in the Enallagma damselfly assemblages of permanent lakes. Ecology, vol. 71, no. 1 , p. $83-98$.

-, 1995. Morphological evolution mediated by behavior in the damselflies of two communities. Evolution, vol. 49, no. 4, p. $749-769$.

McPEEK, MA., SCHROT, AK. and BROWN, JM., 1996. Adaptation to predators in a new community: swimming performance and predator avoidance in damselflies. Ecology, vol. 77, no. 2, p. 617-629.

MILL, PJ. and PICKARD, RS. 1975. Jet-propulsion in Anisopteran dragonfly. Journal of Comparative Physiology B, vol. 97 , no. 4, p. 329-338.

MORIN, PJ., 1984. The impact of fish exclusion on the abundance and species composition of larval odonates: results of short-term experiments in a North Carolina farm pond. Ecology, vol. 65, no. 1, p. 53-60.

NEEDHAM, JG., WESTFALL, MJ., JR. and MAY, ML., 2000. Dragonflies of North America. Scientific Publishers, Gainsville.

OLESEN, J., 1972. The hydraulic mechanism of labial extension and jet propulsion in dragonfly nymphs. Journal of Comparative Physiology A-Sensory Neural and Behavioral Physiology, vol. 81, no. 1, p. 53-55.

PIERCE, CL. 1988. Predator avoidance, microhabitat shift, and risk-sensitive foraging in larval dragonflies. Oecologia (Berlin), vol. 77 , no. 1, p. 81-90.
PIERCE, CL., CROWLEY, PH. and JOHNSON, DM., 1985. Behavior and ecological interactions of larval Odonata. Ecology, vol. 66 , no. 5, p. 1504-1512.

PRITCHARD, G., 1964. The prey of dragonfly larvae in ponds in northern Alberta. Canadian Journal of Zoology, vol. 42, p. $785-800$.

-, 1965. Prey capture by dragonfly larva. Canadian Journal of Zoology, vol. 43, p. 271-289.

-, 1966. On the morphology of the compound eyes of dragonflies (Odonata: Anisoptera), with special reference to their role in prey capture. Proceedings of the Royal Entomological Society of London, vol. 41, no. 1-3, p. 1-8.

RICKLEFS, RE. and MILES, DB., 1994. Ecological and evolutionary inferences from morphology: an ecological perspective. In Ecological Morphology: Integrative Organismal Biology. WAINWRIGHT, PC. and REILLY, SMCP. (eds), The University of Chicago Press VL -, p. 13-41.

SAZIMA, I. and ZAMPROGNO, C., 1985. Use of water hyacinths as shelter, foranging place, and transport by young piranhas, Serrasalmus spilopleura. Environmental Biology of Fishes, vol. 12, no. 3, p. 237-240.

STRONG, DR., SYSKA, LA. and SIMBERLOFF, DS., 1979. Tests of community-wide character displacement against null hypotheses. Evolution, vol. 33, no. 3, p. 897-913.

WELLBORN, GA. and ROBINSON, JV., 1987. Microhabitat selection as an antipredator strategy in the aquatic insect Pachydiplax longipennis Burmeister (Odonata: Libellulidae). Oecologia (Berlin), vol. 71, no. 2, p. 185-189.

WESTFALL, MJ., JR., 1984. Odonata. In An Introduction to the Aquatic Insects of North America. MERRITT, RW. and CUMMINS, KWCP. (eds), Kendall / Hunt Publishing Company VL - Dubuque, Iowa, p. 126-176. 
